LAWRENCE LIVERMORE NATIONAL LABORATORY

\section{Asian Summer Monsoon Diagnostics for CAM5.1}

K. R. Sperber, M. F. Wehner

October 26, 2012 
This document was prepared as an account of work sponsored by an agency of the United States government. Neither the United States government nor Lawrence Livermore National Security, LLC, nor any of their employees makes any warranty, expressed or implied, or assumes any legal liability or responsibility for the accuracy, completeness, or usefulness of any information, apparatus, product, or process disclosed, or represents that its use would not infringe privately owned rights. Reference herein to any specific commercial product, process, or service by trade name, trademark, manufacturer, or otherwise does not necessarily constitute or imply its endorsement, recommendation, or favoring by the United States government or Lawrence Livermore National Security, LLC. The views and opinions of authors expressed herein do not necessarily state or reflect those of the United States government or Lawrence Livermore National Security, LLC, and shall not be used for advertising or product endorsement purposes.

This work performed under the auspices of the U.S. Department of Energy by Lawrence Livermore National Laboratory under Contract DE-AC52-07NA27344. 


\title{
Asian Summer Monsoon Diagnostics for CAM5.1
}

\author{
K. R. Sperber ${ }^{1}$ and M. F. Wehner ${ }^{2}$ \\ ${ }^{1}$ Program for Climate Model Diagnosis and Intercomparison \\ Lawrence Livermore National Laboratory \\ P.O. Box 808, L-103 \\ Livermore, CA 94551 USA \\ Email: sperber1@1lnl.gov \\ ${ }^{2}$ Lawrence Berkeley National Laboratory \\ 1 Cyclotron Rd, MS50F \\ Berkeley, California 94720 USA
}


Table 1: Pattern correlations between models and observations. For precipitation, the models are validated against GPCP, and for winds the models are validated against JRA25. For the precipitation and 850hPa JJAS wind climatologies the pattern correlations are calculated over the region region $40^{\circ} \mathrm{E}-160^{\circ} \mathrm{E}, 20^{\circ} \mathrm{S}-50^{\circ} \mathrm{N}$. For the annual cycle of $70^{\circ} \mathrm{E}-90^{\circ} \mathrm{E}$ averaged rainfall the pattern correlation is over the domain $10^{\circ} \mathrm{S}-30^{\circ} \mathrm{N}$, for May-September. For the JJAS El Nino precipitation anomalies the pattern correlation is over the region $60^{\circ} \mathrm{E}-100^{\circ} \mathrm{E}, 0^{\circ}-30^{\circ} \mathrm{N}$. For the East Asian Summer Monsoon the JJA precipitation and $850 \mathrm{hPa}$ wind anomalies are calculated over the region $100^{\circ} \mathrm{E}-140^{\circ} \mathrm{W}, 0^{\circ}-50^{\circ} \mathrm{N}$. For rainfall, the observational pattern correlation is between CMAP and GPCP. For $850 \mathrm{hPa}$ wind climatology, the observational pattern correlation is between ERA40 (1961-1999) and JRA25. For $850 \mathrm{hPa}$ wind anomalies over the East Asian Summer Monsoon region, the observational pattern correlation is between NCEP-NCAR Reanalysis and JRA25. Bold entries indicate the model with the highest pattern correlation.

\begin{tabular}{|l|l|l|l|l|l|l|}
\hline & $\begin{array}{l}\text { Pr } \\
\text { Clim. }\end{array}$ & $\begin{array}{l}850 \mathrm{hPa} \\
\text { Clim. }\end{array}$ & $\begin{array}{l}\text { Pr Ann. } \\
\text { Cycle }\end{array}$ & $\begin{array}{l}\text { Pr vs. } \\
\text { Nino3.4 } \\
\text { SSTA }\end{array}$ & $\begin{array}{l}\text { Pr vs. } \\
\text { EASM } \\
\text { WF } \\
\text { index }\end{array}$ & $\begin{array}{l}\text { 850hPa } \\
\text { vs. } \\
\text { EASM } \\
\text { WF } \\
\text { index }\end{array}$ \\
\hline Obs & 0.924 & 0.985 & 0.883 & 0.778 & 0.959 & 0.989 \\
\hline $0.25^{\circ}$ & 0.657 & 0.898 & 0.696 & -0.030 & 0.672 & 0.913 \\
\hline $1^{\circ}$ & $\mathbf{0 . 7 6 9}$ & $\mathbf{0 . 9 5 8}$ & $\mathbf{0 . 7 3 0}$ & $\mathbf{0 . 1 6 6}$ & 0.780 & $\mathbf{0 . 9 1 7}$ \\
\hline $2^{\circ}$ & 0.739 & 0.948 & 0.640 & -0.033 & $\mathbf{0 . 7 9 4}$ & 0.901 \\
\hline
\end{tabular}


a) GPCP
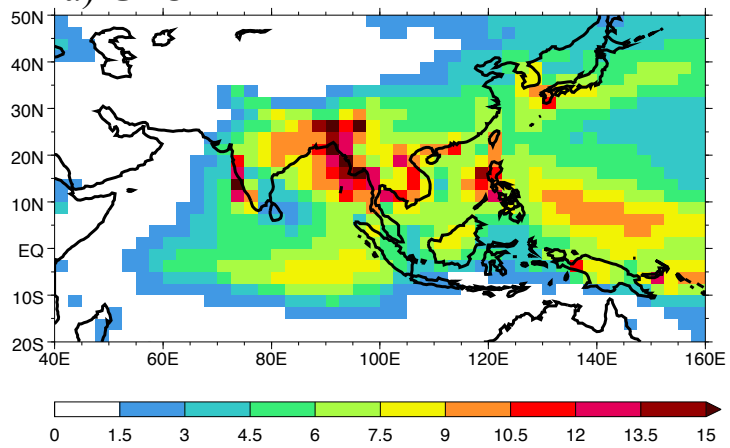

b) $0.25^{\circ}$
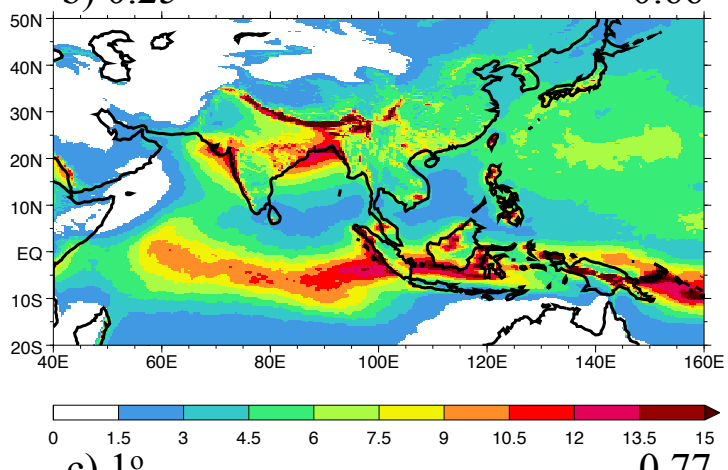

c) $1^{\circ}$
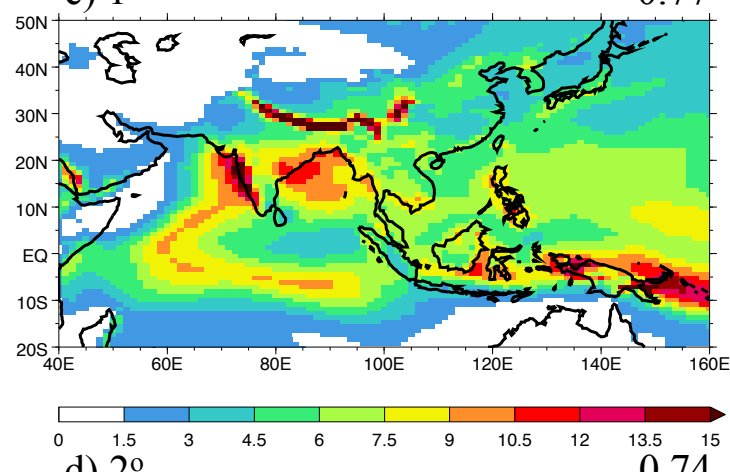

d) $2^{\circ}$

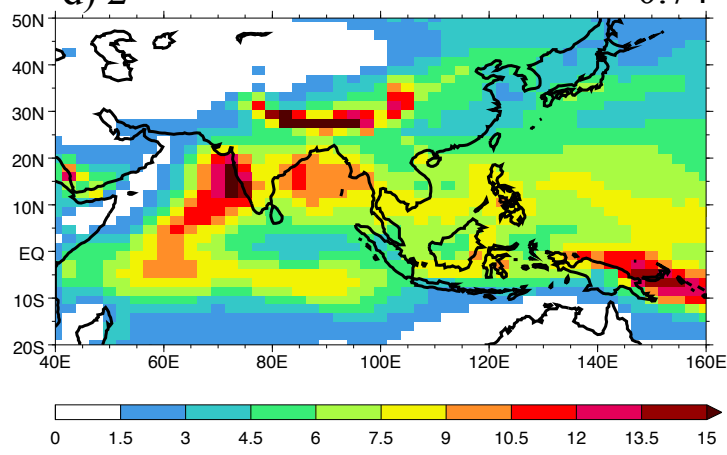

e) CMAP - GPCP
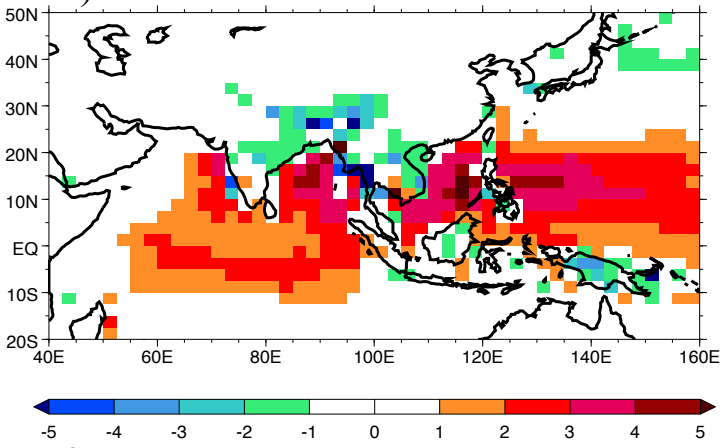

f) $0.25^{\circ}-\mathrm{GPCP}^{-2}$
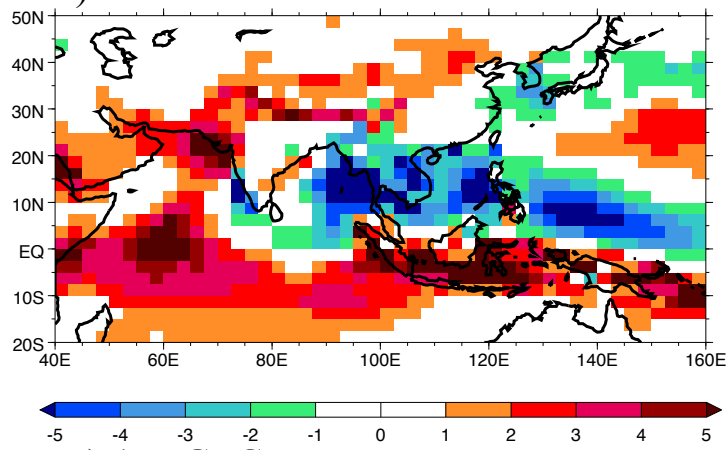

g) $1^{0}-\mathrm{GPCP}^{-2}$
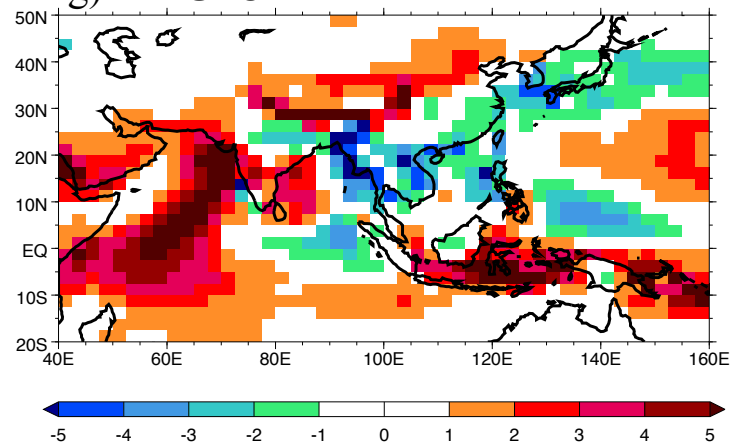

h) $2^{\circ}-$ GPCP

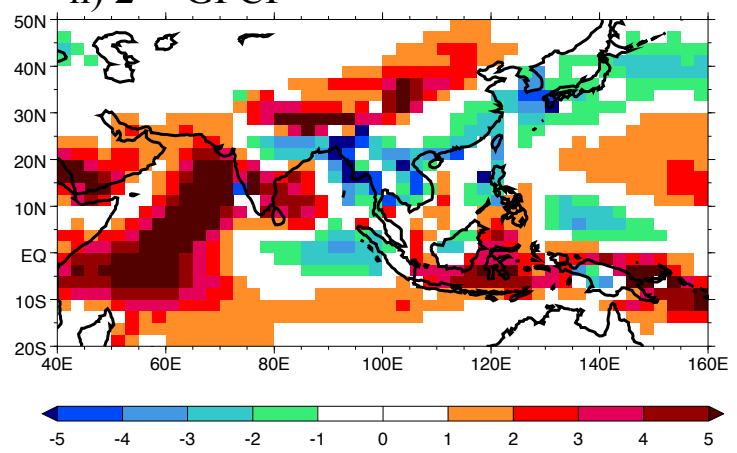

Fig. 1 a-d JJAS precipitation rate climatology from a GPCP, b $0.25^{\circ}$ run, $\mathbf{c} 1^{\circ}$ run, and $\mathbf{d} 2^{\circ}$ run. Also given in $\mathbf{a}$ is the pattern correlation of CMAP with GPCP, and in b-d are the model pattern correlations with GPCP over the region $40^{\circ} \mathrm{E}-160^{\circ} \mathrm{E}, 20^{\circ} \mathrm{S}-50^{\circ} \mathrm{N}$. f (CMAP) minus (GPCP), f-h as b-d but for (model) minus (GPCP). The units are $\left(\mathrm{mm} \mathrm{day}^{-1}\right)$. The difference maps were calculated on the $2.5^{\circ} \times 2.5^{\circ}$ grid used by GPCP. 
a) JRA25

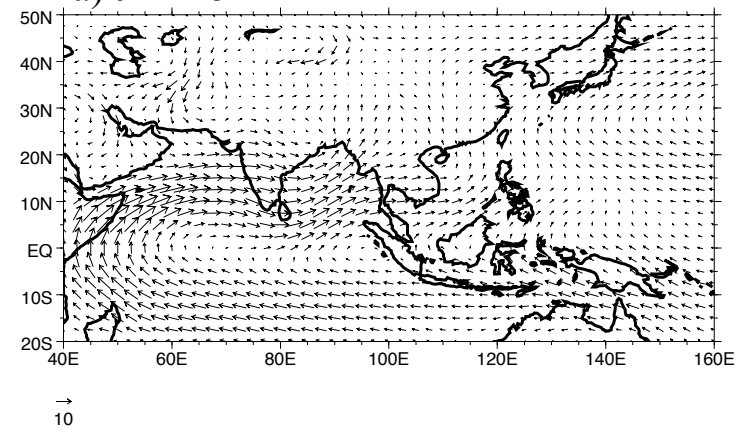

b) $0.25^{\circ}$

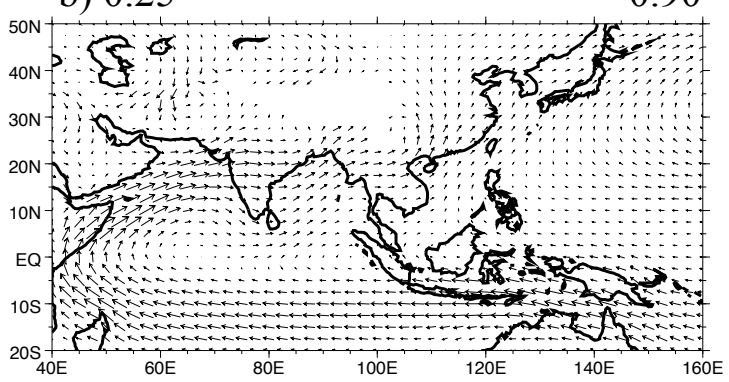

$\overrightarrow{10}$

c) $1^{\circ}$

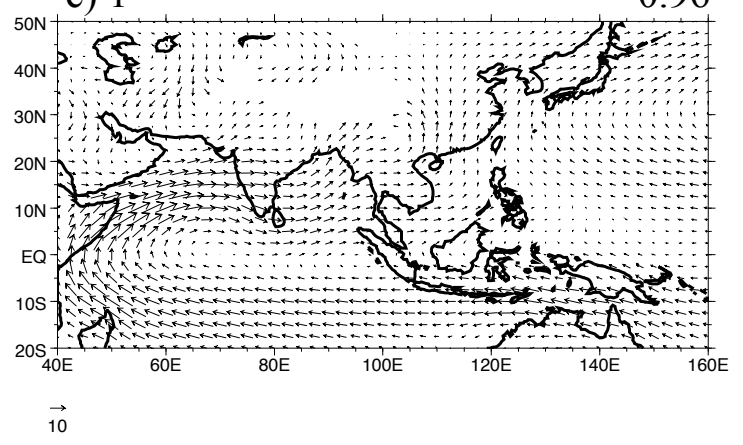

d) $2^{\circ}$

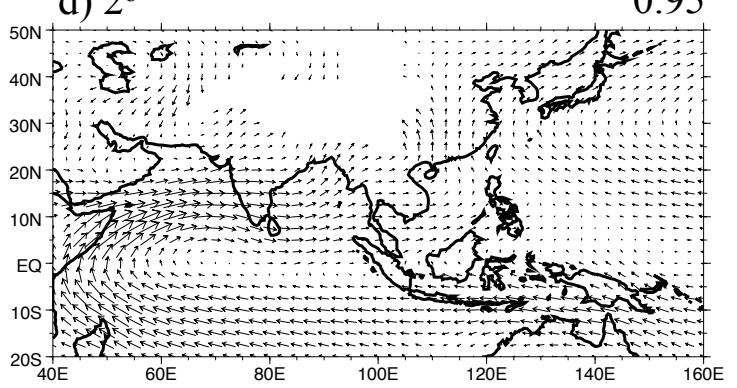

e) ERA40 (1961-99) - JRA25

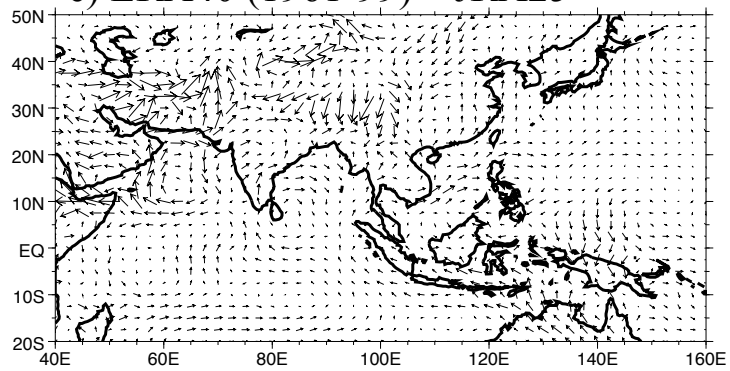

$\overrightarrow{2}$

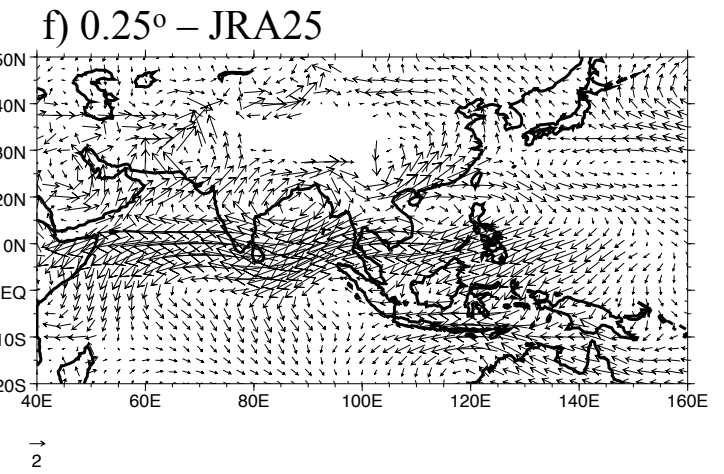

g) $1^{\mathrm{o}}-\mathrm{JRA} 25$

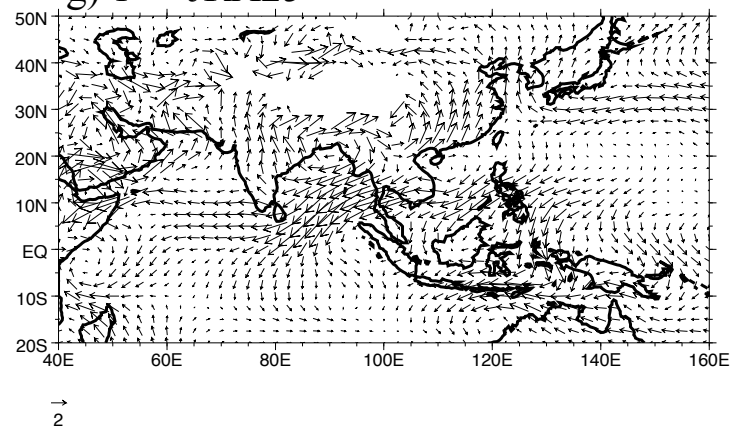

h) $2^{\circ}-$ JRA25

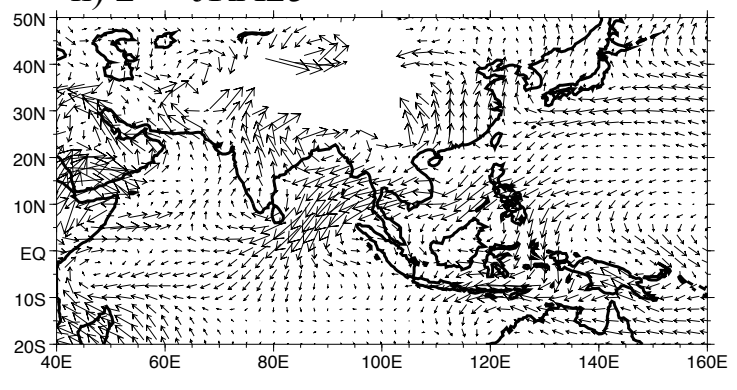

$\overrightarrow{10}$

Fig. 2 a-d JJAS $850 \mathrm{hPa}$ wind climatology from a JRA25, b $0.25^{\circ}$ run, $\mathbf{c} 1^{\circ}$ run, and d $2^{\circ}$ run. Also given in a is the pattern correlation of ERA40 with JRA25, and in b-d are the model pattern correlations with JRA25 over the region $40^{\circ} \mathrm{E}-160^{\circ} \mathrm{E}, 20^{\circ} \mathrm{S}-50^{\circ} \mathrm{N}$. e (ERA40) minus (JRA25), f-h as b-d but for (model) minus (JRA25). The units are $\left(\mathrm{ms}^{-1}\right)$. JRA25 and model data are from 1979-2005, ERA40 is from 1961-1999. The data has been regridded to a $2.5^{\circ} \times 2.5^{\circ}$ grid prior to analysis. 


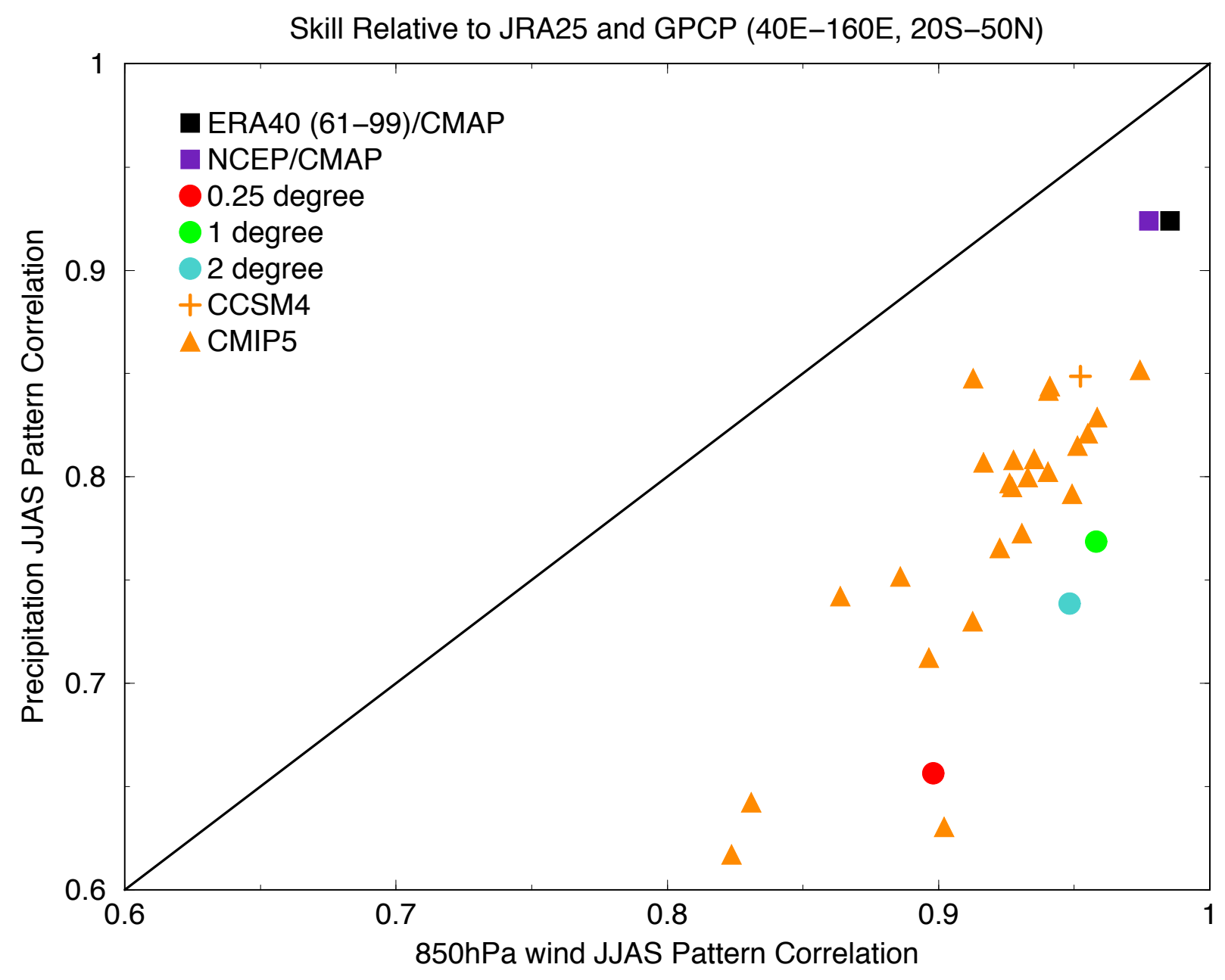

Fig. 3 Scatterplot of the pattern correlation with observations of simulated JJAS 850hPa wind climatology vs. the pattern correlation with observations of simulated JJAS precipitation climatology. The skill is relative to JRA25 and GPCP over the region $40^{\circ} \mathrm{E}-160^{\circ} \mathrm{E}, 20^{\circ} \mathrm{S}-50^{\circ} \mathrm{N}$. 
a) GPCP
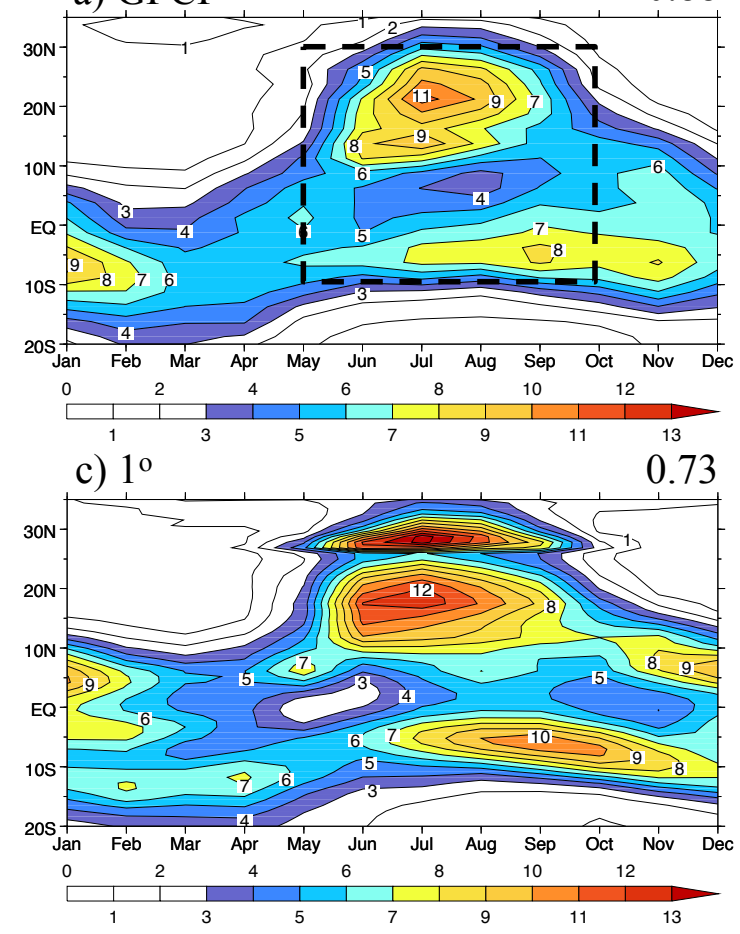

b) $0.25^{\circ}$

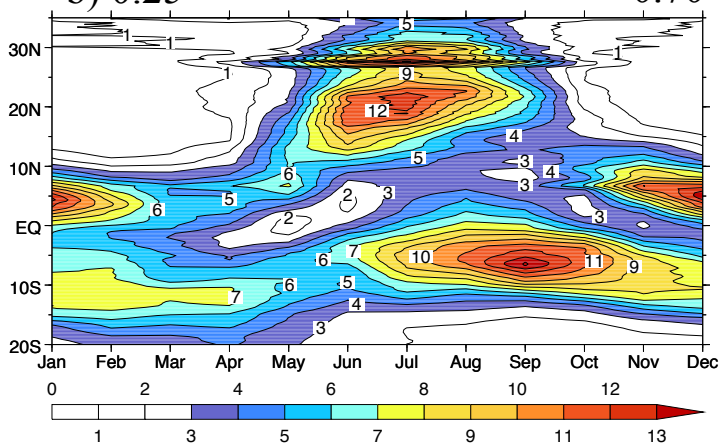

d) $2^{\circ}$

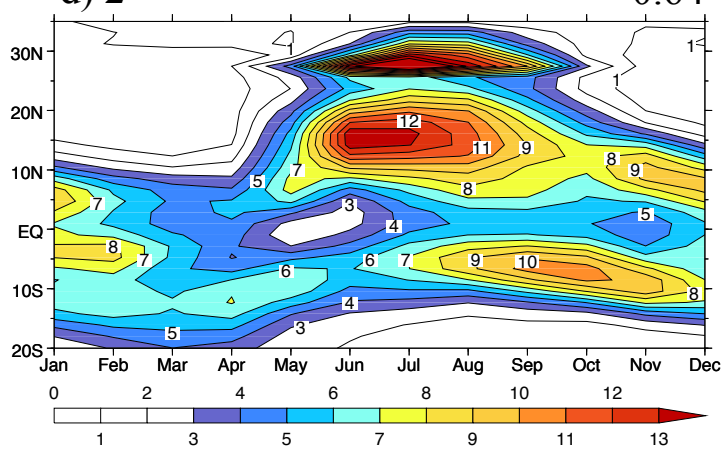

Fig. 4 a-f Annual cycle climatology for rainfall rate averaged between $70^{\circ} \mathrm{E}-90^{\circ} \mathrm{E}$ from a GPCP, $\mathbf{b} 0.25^{\circ}$ run, c $1^{\circ}$ run, and $\mathbf{d} 2^{\circ}$ run. Also given in $\mathbf{b}-\mathbf{d}$ is the pattern correlation of the model with GPCP over the region $10^{\circ} \mathrm{S}-30^{\circ} \mathrm{N}$, for May-September (the dashed region in a). The units are $\left(\mathrm{mm} \mathrm{day}^{-1}\right)$. 

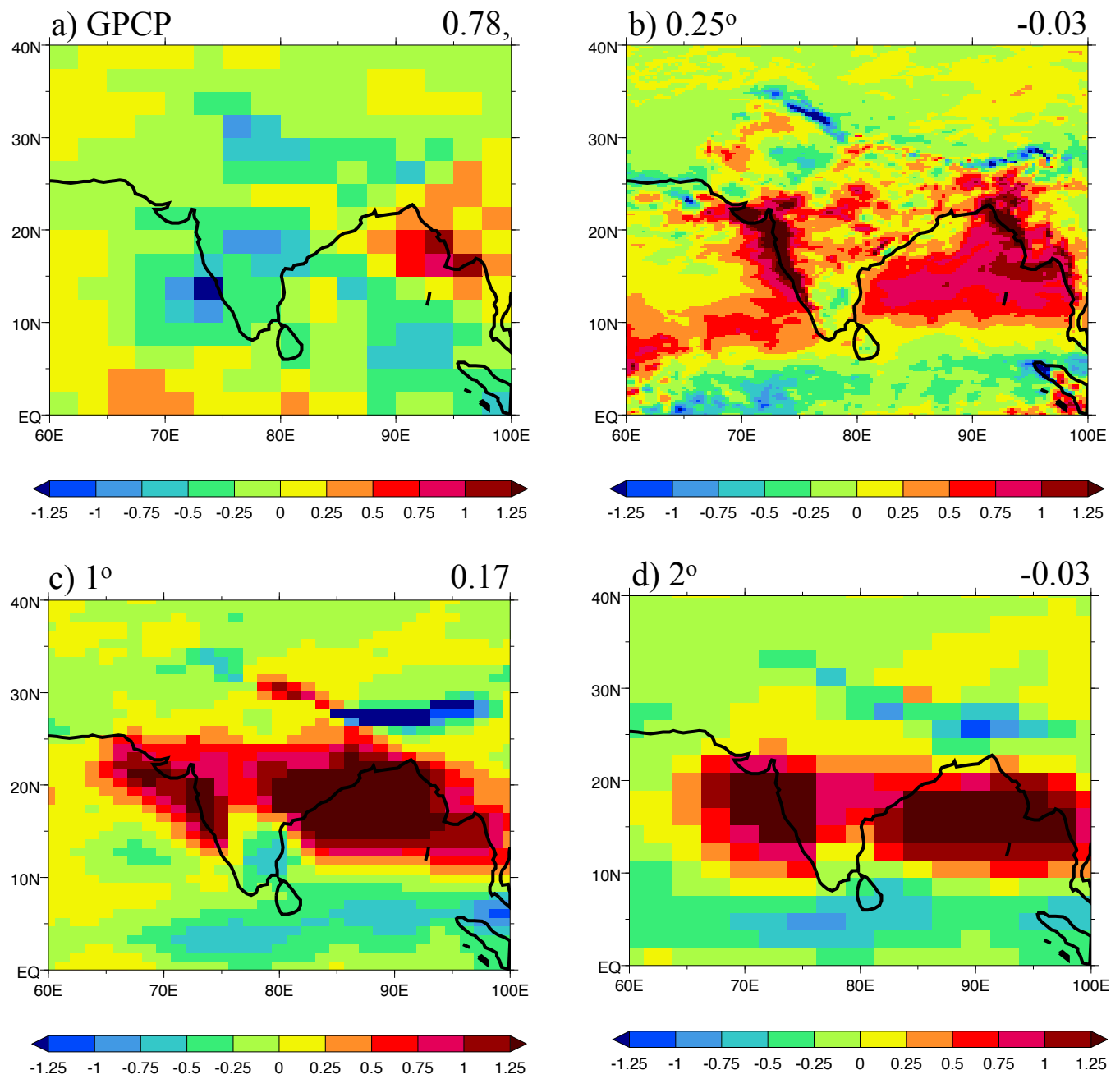

Fig. 5 Interannual JJAS precipitation anomalies $\left(\mathrm{mm} \mathrm{day}^{-1}\right)$ based on linear regression with JJAS NINO3.4 SST anomalies used in the NCEP-NCAR Reanalysis a GPCP rainfall, b $0.25^{\circ}$ run, $\mathbf{c} 1^{\circ}$ run, and $\mathbf{d} 2^{\circ}$ run. The regressions are scaled by one standard deviation of the NINO3.4 SST anomalies. The value in a is the pattern correlation of CMAP with GPCP. b-d the model pattern correlation with GPCP. The skill metrics are calculated over the region $60^{\circ} \mathrm{E}-100^{\circ} \mathrm{E}, 0^{\circ}-30^{\circ} \mathrm{N}$. 
a) JRA25/GPCP

$(0.99,0.96)$

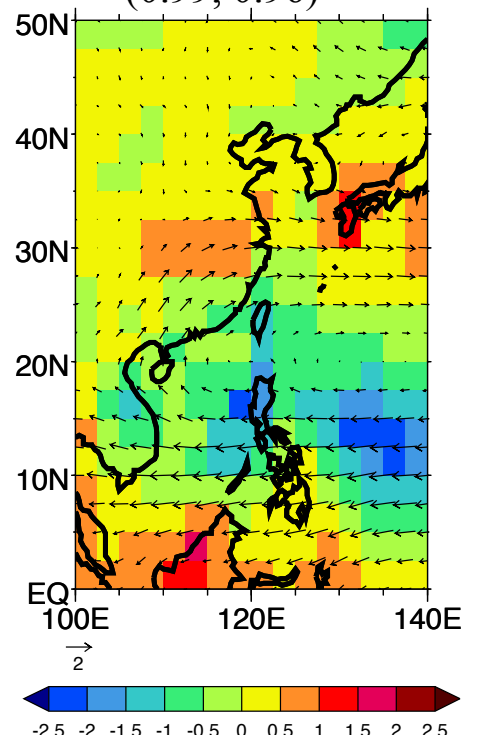

b) $0.25^{\circ}$

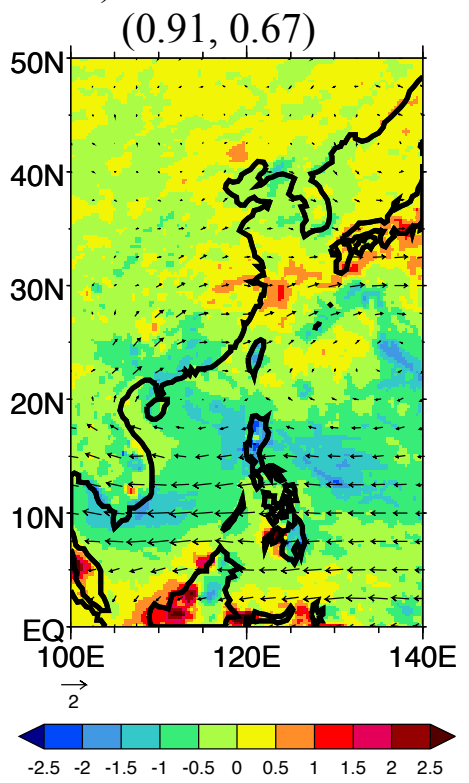

c) $1^{\circ}$

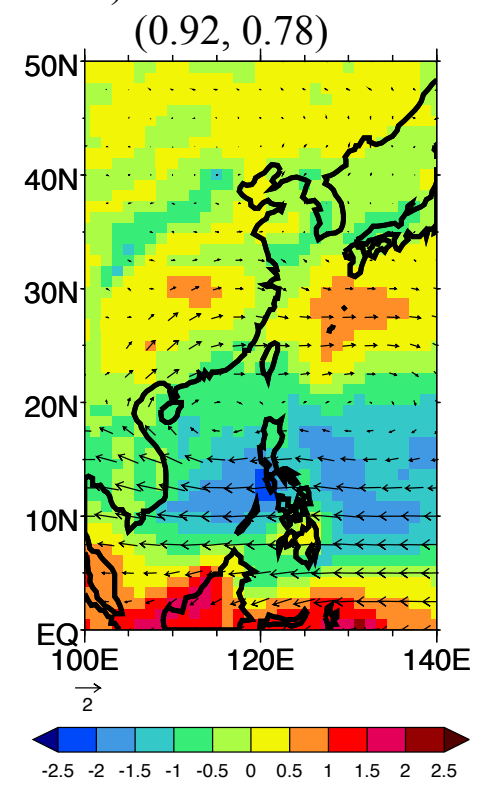

d) $2^{\circ}$

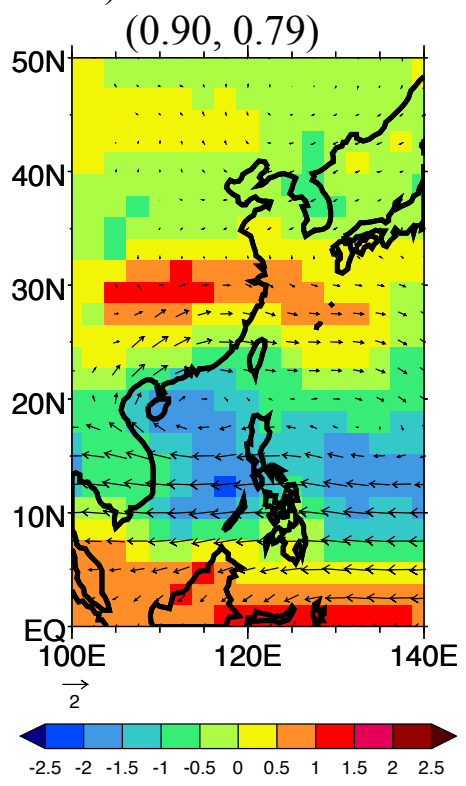

Fig. 6 Interannual East Asian summer monsoon JJA 850hPa wind anomalies and precipitation anomalies based on linear regression with the revised JJA Wang-Fan $850 \mathrm{hPa}$ zonal wind index for a JRA25/GPCP, b $0.25^{\circ}$ run, $\mathbf{c} 1^{\circ}$ run, and $\mathbf{d} 2^{\circ}$ run. Also given in $\mathbf{a}$ is the pattern correlation of JRA25 with NCEP/NCAR Reanalysis and GPCP with CMAP, respectively, and in b-d are the model pattern correlations with JRA25 and GPCP over the region $100^{\circ} \mathrm{E}-140^{\circ} \mathrm{W}, 0^{\circ}-50^{\circ} \mathrm{N}$. The units for the $850 \mathrm{hPa}$ wind anomalies are $\mathrm{ms}^{-1}$ and for precipitation anomalies the units are $\mathrm{mm} \mathrm{day}^{-1}$. The wind vectors are shown on a $2.5^{\circ} \times 2.5^{\circ}$ grid. 
Acknowledgements. For CMIP the U.S. Department of Energy's Program for Climate Model Diagnosis and Intercomparison provides coordinating support and led development of software infrastructure in partnership with the Global Organization for Earth System Science Portals. K. R. Sperber was supported by the Office of Science (BER), U.S. Department of Energy through Lawrence Livermore National Laboratory contract DEAC52-07NA27344. 